\title{
Effect of Second Cycle Pre-induction Chemotherapy in Critically III Burkitt's Lymphoma Children
}

\author{
Emad Moussa $^{1,2}$, Asmaa Hamoda ${ }^{2,3}$, Samah Semary $^{2,4}$, Marwa Romeih ${ }^{5,6}$, Randa Amin ${ }^{7,8}$, \\ Omneya Hassanin? \\ ${ }^{1}$ Department of Clinical Oncology, Menufiya University, Shebeen, Egypt \\ ${ }^{2}$ Department of Pediatric Oncology, Children Cancer Hospital Egypt, Cairo, Egypt \\ ${ }^{3}$ Department of Pediatric Oncology, National Cancer Institute, Cairo University, Cairo, Egypt \\ ${ }^{4}$ Department of Clinical Oncology, Faculty of Medicine, Beni-Suef University, Beni-Suef, Egypt \\ ${ }^{5}$ Department of Radiodiagnosis, Faculty of Medicine, Helwan University, Helwan, Egypt \\ ${ }^{6}$ Department of Radiodiagnosis, Children Cancer Hospital Egypt, Cairo, Egypt \\ ${ }^{7}$ Department of Pathology, Faculty of Medicine, Assiut University, Assiut, Egypt \\ ${ }^{8}$ Department of Pathology, Children Cancer Hospital Egypt, Cairo, Egypt \\ ${ }^{9}$ Department of Clinical Research, Children Cancer Hospital Egypt, Cairo, Egypt
}

\section{Email address:}

samahsemary@57357.com (S. Semary),samah.semary@57357.org (S. Semary)

\section{To cite this article:}

Emad Moussa, Asmaa Hamoda, Samah Semary, Marwa Romeih, Randa Amin, Omneya Hassanin. Effect of Second Cycle Pre-induction Chemotherapy in Critically Ill Burkitt's Lymphoma Children. Cancer Research Journal. Vol. 7, No. 1, 2019, pp. 25-32.

doi: $10.11648 /$ j.crj.20190701.14

Received: February 16, 2019; Accepted: March 25, 2019; Published: April 18, 2019

\begin{abstract}
Advanced stage Burkiit's lymphoma (BL) is associated with tumor burden. Toxicities from intensive therapies are significant. The objectives of this study were to analyze the outcome of patients who could not receive induction chemotherapy on time, and were given a $2^{\text {nd }}$ pre-phase (CVP), and to measure the impact of delay on disease outcome. It is a retrospective non randomized study included pediatric patients, suffering from Burkitt's Lymphoma over 8 years period in CCHE. The result showed that, four hundred and eight patients were diagnosed as Burkitt's Lymphoma from July 2007 till October 2015 , 286 patients $(70.1 \%)$ received induction on time as per protocol, while 122 patients $(29.9 \%)$ were not fit to receive their induction chemotherapy on due time. The delay ranged from 6-45 days. While forty five patients (36.88\%) out of the delayed patients received $2^{\text {nd }}$ CVP, 16 patients $(13.1 \%)$ showed relapse/progression. OS among delayed patients who received $2^{\text {nd }}$ CVP versus those who were delayed and were able to receive full induction chemotherapy was $(76.1 \%)$, (88.7\%) respectively. OS in patients who were delayed versus those who were not delayed was $(84 \%),(85.9 \%)$ respectively. In conclusion, in critically ill patients delay of chemotherapy in induction phase is important to reduce morbidity and mortality. The delay of chemotherapy has no impact on OS in Burkitt's lymphoma children. A second pre-phase therapy in our opinion should not be adopted for all critical ill patients who will not tolerate intensive therapy during early phases of treatment, but instead we recommend a recovery from organ toxicity and starting intensive therapy (COPADM) rather than giving $2^{\text {nd }}$ CVP with careful surveillance of disease progression.
\end{abstract}

Keywords: Burkitt's Lymphoma, Second Pre-Induction Phase, Chemotherapy Toxicity

\section{Introduction}

Lymphomas represent more than $15 \%$ of malignancies in children and adolescents [1]. Non-Hodgkin's lymphomas (NHL) in children and adolescents are classified according to the WHO classification based on the immunophenotype and developmental stage of the lymphoid cells. The mature B-cell NHL (Burkitt lymphoma account for about $46 \%$ of pediatric NHL, and diffuse large cell B-NHL account for about $8 \%$ of pediatric NHL, and high grade B cell lymphoma) represent more than half of pediatric NHL, the other main subtypes are 
the precursor B and T-cell NHL (lymphoblastic lymphoma which account for about $21 \%$ of pediatric NHL), and anaplastic large $\mathrm{T}$ cell lymphoma which is presented by about $13 \%$ of pediatric NHL [2]. Burkitt's lymphoma was associated with poor outcomes before the advent of high intensity chemotherapy, probably because of its high proliferative rate [3].

Advanced stage BL is often associated with heavy tumor burden 4-5. Toxicities reported from many of these intensive therapies are significant, including neurotoxicity, hematological toxicity, nephrotoxicity, hepatotoxicity, and cardiotoxicity $[4,5]$.

\section{Aim of the Work}

To analyze the outcome of Burkitt's lymphoma patients who could not receive induction chemotherapy on time as per LMB 96 protocol at day 8 post pre-induction phase chemotherapy with cyclophosphamide, vincristine, prednisone, (CVP) because of their critical condition, so they were delayed, and only received a second cycle preinduction phase chemotherapy, (CVP). In a critical metabolic situation with impaired renal function (or very bulky disease) it may be advisable to give consecutive (CVP). Patients with renal failure, creatinine clearance $<60 \mathrm{ml} / \mathrm{min}$, septicemia or other sepsis or grade $3 / 4$ organ toxicity, transaminases $>$ $10 \mathrm{xN}$ for more than 48 hours, a further course of CVP should be considered.

Our aim in this study was to measure the impact of this delay and the second CVP on disease outcome.

\section{Patients and Methodology}

A retrospective, non-Randomized study in which all newly diagnosed Burkitt's lymphoma / leukemia patients less than 18 years old were included from July 2007 till end of October 2015 in Children Cancer Hospital Egypt (CCHE). Patients were treated according LMB - 96 protocols [1].

Median follow up was 38.7 months (range $0.49 \mathrm{~m}$ to $106.48 \mathrm{~m})$.

NHL LBM 96 protocol [1]:

Group A: Completely resected stage I or completely resected abdominal stage II lesions, and was treated by 2 cycles of COPAD without pre induction phase chemotherapy.

Group B: All cases not eligible for group A or group C , and was treated with pre-induction phase CVP, followed by 2 cycles induction COPADM3, followed by 2 cycles consolidations CYM, and the points of evaluation were post pre-induction phase CVP, and post CYM1.

Group C: CNS involvement, and/or bone marrow involvement $\geq 25 \%$ blasts, and/or less than $25 \%$ reduction of the initial mass at time of evaluation post pre-induction phase chemotherapy CVP evaluated by CT, followed by 2 cycles induction in the form of COPADM8, followed by 2 cycles of consolidations in the form of $\mathrm{CYV}$, then received 4 cycles maintenance, and the points of evaluation for them were after pre-induction phase, and after CYVII, Table 1.
All patients of group B and group $\mathrm{C}$ received pre-induction chemotherapy phase (CVP) post confirmation of the diagnosis as Burkitt's Lymphoma by pathology, then as per LMB 96, evaluation was done at day 7 of CVP, if good response and more than $25 \%$ reduction of the initial mass, the patient continued as group $\mathrm{B}$ and if poor response, the patient is upgraded to group $\mathrm{C}$, then both group $\mathrm{B}$ and group $\mathrm{C}$ received induction phase chemotherapy.

Among group $\mathrm{B}$ and $\mathrm{C}$, Patients might receive a second pre-induction phase CVP if they suffered from: Renal failure, Septicemia, and Grade 3/4 organ toxicity.

Eligible patients less than 18 years old, had DE novo Burkitt's lymphoma confirmed by pathological diagnostic methods, initial work up was done for them including full laboratory tests, computed tomographic scans for the whole body, and a bone marrow aspirate and bilateral bone marrow biopsy. All the patients and their legal guardians provided written informed consent. The Kaplan-Meier method was used to estimate overall survival, event free survival for all groups of the study. We compared induction deaths among patients who were delayed to receive their induction chemotherapy for their critical condition and patients who were not delayed and received their induction chemotherapy on time as per protocol. We also compared between the outcome for delayed patients and patients received their induction chemotherapy on time.

\section{Results}

Four hundreds and eight patients were diagnosed as Burkitt's Lymphoma/leukemia during the whole study period (8 years), $286(70.1 \%)$ received induction chemotherapy on time. One hundred twenty two patients $(29.9 \%)$ were not fit to receive their induction chemotherapy, due to critical metabolic situation with impaired renal function, very bulky disease, renal failure, creatinine clearance $<60 \mathrm{ml} / \mathrm{min}$, septicemia or other sepsis, grade $3 / 4$ organ toxicity, transaminases $>10 \mathrm{xN}$ for more than 48 hours, a further course of CVP should be considered so they were delayed, table 2. Out of the 122 patients $(29.9 \%)$ who were delayed for induction chemotherapy, 45 patients $(36.8 \%)$ received 2nd CVP, while 77 patients (63.1\%) did not receive any chemotherapy, as therapy was postponed till improvement of clinical condition, or recovery from organ dysfunction, table 3. The range of delay was from 6-45 days, while the mean time for delay was 19.48 days. Out of 45 patients who received second CVP, 26 patients $(57.7 \%)$ had stage III, while 19 patients $(42.3 \%)$ had stage IV, 20 patients $(44.5 \%)$ were group B, while 25 patients $(55.5 \%)$ were group C, table 4. Twenty one patients $(46.6 \%)$ were delayed out of septicemia, 20 patients $(44.4 \%)$ were delayed because of organ toxicity, and 4 patients $(8.8 \%)$ were delayed because of renal impairment, table 5 .

Twenty six patients $(21.3 \%)$ out of the delayed patient died table 6 . Nine of them $(7.3 \%)$ died during induction therapy. Three of them (2.4\%) received 2 nd CVP, and died later, table 7, 8. One of them was stage IV with bone marrow 
infiltration, at time of induction he had ascites, suffered from DIC and sepsis, delayed about 15 days, and died from septicemia.

The second one was stage III, had huge pelvi-abdominal mass, at time of induction had tumor lysis syndrome, and acidosis. Then was delayed for about 13 days and received 2nd CVP, and died out of septicemia.

The third one was stage IV with bone marrow and CNS infiltration (group c), at time of induction had bilateral pleural effusion and neutropenia, delayed about 18 days, and received 2nd CVP, and died during induction with septicemia.

Six patients $(66.6 \%)$ were delayed to start induction due to their critical condition, but they received COPADM3/COPADM8 according to their group whenever their clinical condition permitted, but unfortunately died eventually, table 8 . Three patients died out of septicemia, one patient died from heart failure, one patient died from respiratory failure due to massive pleural effusion, and one patient died from MTX toxicity. Seventeen patients (65.3\%) out of the delayed patients died away from induction later during the rest of the protocol.

Seven patients $(5.7 \%)$ were critically ill at time of induction and received 2nd CVP, were alive at end of induction but died later during protocol , 2 patients of them delayed out of tumor lysis syndrome, 2 patients had septic shock, one patient had CNS insult in the form of acute encephalopathy, and 2 patients had 3rd space. The last one suffered severe neutropenia.

One patient died out of disease progression and died on first line chemotherapy treatment, 6 of them (4.9\%) died on 2nd line of treatment out of relapse, table 9.

Ten patients $(58.8 \%)$ were delayed from their date of induction due to their critically ill condition but received COPADM3/COPADM8 according to their group, and did not die at induction but died later during rest of the protocol, seven of them died out of sepsis, while three patients died out of disease progression, table 9.
The overall survival among those who were delayed and received CVP was $76.1 \%$ (St. Error 7\%), while among those who were delayed and received COPADM was $88.7 \%$ (St. Error 4\%) with no significant $\mathrm{P}$ value (P value 0.369 ), figure 1. The Event Free Survival among the 2 groups were $71.5 \%$ (57.2- 85.8) and73.3\% (62.5-84.1) respectively with no significant $\mathrm{P}$ value ( $\mathrm{P}$ value 0.810 ), figure 2 .

We also analyzed patients who received their induction on time and died during induction who were 15 patients $(5.2 \%)$ (Table 8). Four patients started HDMTX (CPADM3/COPADM8) with 3rd space (pleural effusion or ascites), two patients were in tumor lysis syndrome, four patients had prolonged severe neutropenia, two patients were in sepsis, one patient had elevated liver enzymes, and two patients had CNS complications.

All of them died in induction, seven patients died out of septicemia, three patients died from CNS complications, three patients died out MTX toxicity, and two patients died from typhilitis.

Out of the delayed patients 16 patients (13.1\%) showed relapse or disease progression, 4 of them (3.2\%) delayed and received 2nd CVP, 3 patients (2.4\%) delayed and received COPADM, all of them received $2^{\text {nd }}$ line salvage chemotherapy with no response and died out of disease, while 6 patients $(4.9 \%)$ were delayed and relapsed or progressed then received $2^{\text {nd }}$ line salvage chemotherapy and alive in complete remission, table 9, with overall survival $84 \%$ St. Error $3.7 \%$.

From the non-delayed patients, 38 patients $(13.2 \%)$ had relapse or disease progression, 33 of them (11.5\%) died from disease progression, while only 5 are alive in complete remission with overall survival $85.9 \%$ St. Error 2.2\% (Table $10)$, with no significant $P$ value between the delayed and nondelayed patients (P value 0.602) figure 3, and the Event Free Survival among the 2 groups were $72.7 \%$ (64.3-81.1), and $77.6 \%(72.3-82.9)$ respectively without significant statistical difference (P value 0.169) figure 4.

Table 1. LMB -96 chemotherapy protocol 1 .

\begin{tabular}{|c|c|c|c|c|}
\hline & Pre-induction phase & Induction X 2 & Consolidation x2 & Continuation $\mathrm{x} 4$ \\
\hline Group A & -- & COPAD & --- & --- \\
\hline Group B & & COPADM3 & COPADM8 & ---- \\
\hline Group C & & CYM & CYV & Sequences \\
\hline
\end{tabular}

Group A: Completely resected stage I or completely resected abdominal stage II lesions.

Group B: All cases not eligible for Group A or Group C

Group C: CNS involvement and/or bone marrow involvement $\geq 25 \%$ blasts

Table 2. Classification of patients into patients received induction chemotherapy on time and others who delayed from time of induction.

\begin{tabular}{llll}
\hline & Total no. of patients & Delayed patients & Patients not delayed \\
\hline No. of patients & 408 & 122 & 286 \\
Percent & $100 \%$ & $29.9 \%$ & $70.9 \%$ \\
\hline
\end{tabular}

Table 3. Classification of patients into delayed patients and received $2^{\text {nd }} C V P$, and delayed patients and did not received 2 ndCVP.

\begin{tabular}{|c|c|c|c|}
\hline & Total no. of delayed patients & $\begin{array}{l}\text { delayed patients and received } 2^{\text {nd }} \\
\text { CVP }\end{array}$ & $\begin{array}{l}\text { delayed patients and did not } \\
\text { received } 2 \text { ndCVP }\end{array}$ \\
\hline No of patients & 122 & 45 & 77 \\
\hline Percent & $100 \%$ & $36.8 \%$ & $63.1 \%$ \\
\hline
\end{tabular}


Table 4. Characteristics of delayed patients and received 2 nd CVP.

\begin{tabular}{lll}
\hline & No. of patients & Percent \\
\hline Stage III & 26 & $57.7 \%$ \\
Stage IV & 19 & $42.2 \%$ \\
Group B & 20 & $44.4 \%$ \\
Group C & 25 & $55.5 \%$ \\
\hline
\end{tabular}

Table 5. Cause of delayed induction chemotherapy.

\begin{tabular}{llll}
\hline $\begin{array}{l}\text { Cause of } \\
\text { delay }\end{array}$ & Septicemia & Organ toxicity & Renal impairement \\
\hline No of patients & 21 & 20 & 4 \\
Percent & $46.6 \%$ & $44.4 \%$ & $8.8 \%$ \\
\hline
\end{tabular}

Table 8. Induction Deaths.

\begin{tabular}{lllll}
\hline & Induction Deaths & Delayed, received 2 ${ }^{\text {nd }}$ CVP & Delayed, received COPADM & Critically III, not delayed \\
\hline Number & 24 & 3 & 6 & 15 \\
Percentage $\%$ & $100 \%$ & $12.5 \%$ & $25 \%$ & $62.5 \%$ \\
\hline
\end{tabular}

Table 9. Outcome of Delayed Patients.

\begin{tabular}{|c|c|c|c|c|c|c|c|c|}
\hline & Total & $\begin{array}{l}\text { Relapsed } \\
(2 n d C V P)\end{array}$ & $\begin{array}{l}\text { Relapsed } \\
\text { (COPADM) }\end{array}$ & $\begin{array}{l}\text { Delayed } \\
\text { (Sepsis) }\end{array}$ & $\begin{array}{l}\text { Delayed } \\
\text { (Induction) }\end{array}$ & Relapsed/alive & $\begin{array}{l}\text { Delayed } \\
\text { (relapsed) }\end{array}$ & $\begin{array}{l}\text { Delayed } \\
\text { (Died) }\end{array}$ \\
\hline Number & 122 & 7 & 3 & 7 & 9 & 6 & 16 & 26 \\
\hline Percentage & $100 \%$ & $3.2 \%$ & $2.4 \%$ & $5.7 \%$ & $7.3 \%$ & $4.9 \%$ & $13.1 \%$ & $21.3 \%$ \\
\hline
\end{tabular}

Table 10. Relapse among non-delayed Patients.

\begin{tabular}{|c|c|c|c|c|}
\hline & Not-Dealyed & $\begin{array}{l}\text { Not-Delayed } \\
\text { Died relapsed/progression }\end{array}$ & $\begin{array}{l}\text { Not-Delayed } \\
\text { Alive relapsed/progression }\end{array}$ & No.of Not-Delayed \\
\hline No. of patients & 286 & 33 & 5 & 38 \\
\hline Percentage $\%$ & $100 \%$ & $11.53 \%$ & $1.74 \%$ & $13.9 \%$ \\
\hline
\end{tabular}

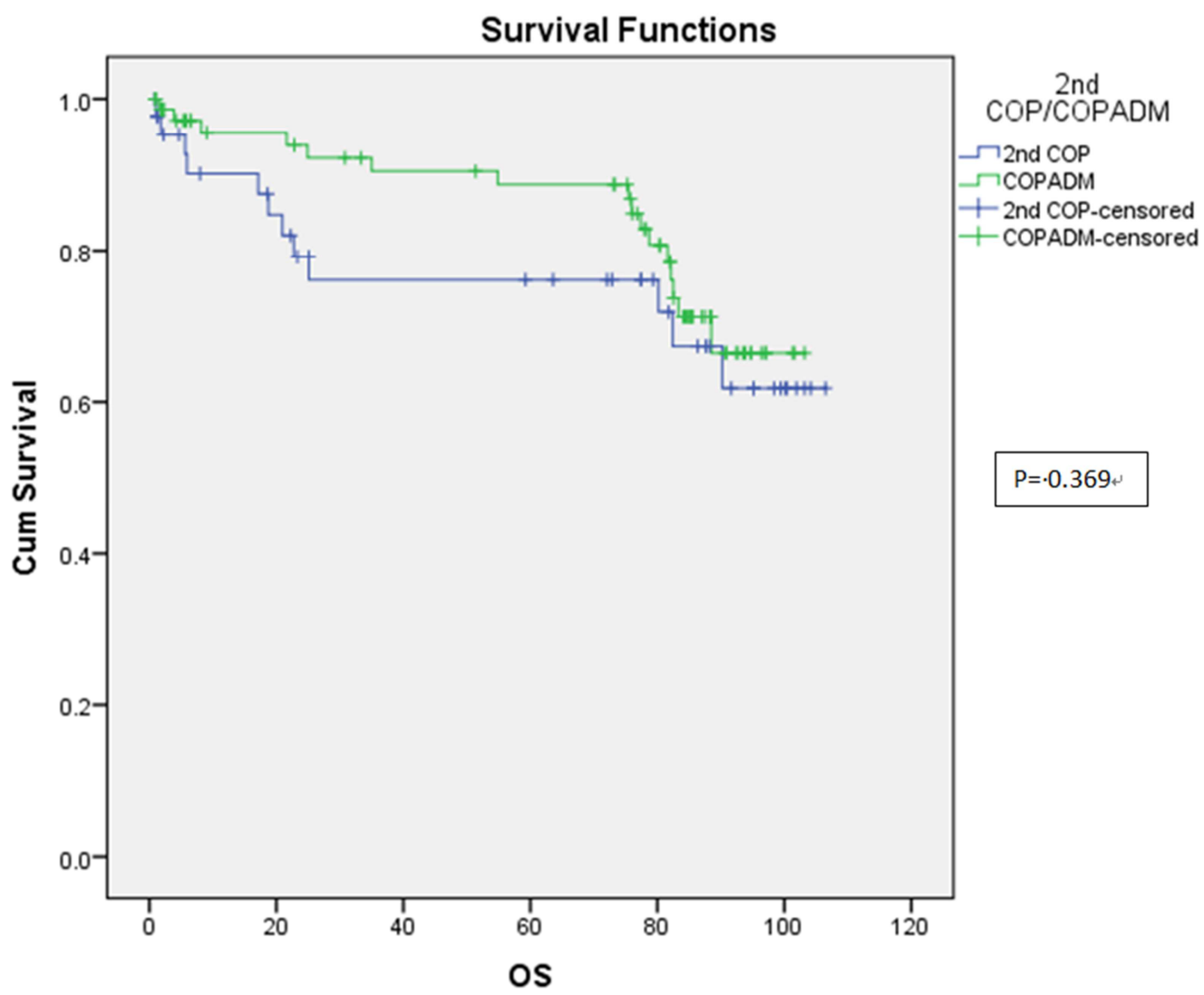

Figure 1. 5 years overall survival among delayed patients who received $2^{\text {nd }}$ CVP was $76.1 \%$ (st. error $7 \%$ ). Versus delayed patients who received COPADM was $88.7 \%$ ( st, error $4 \%$ ). 


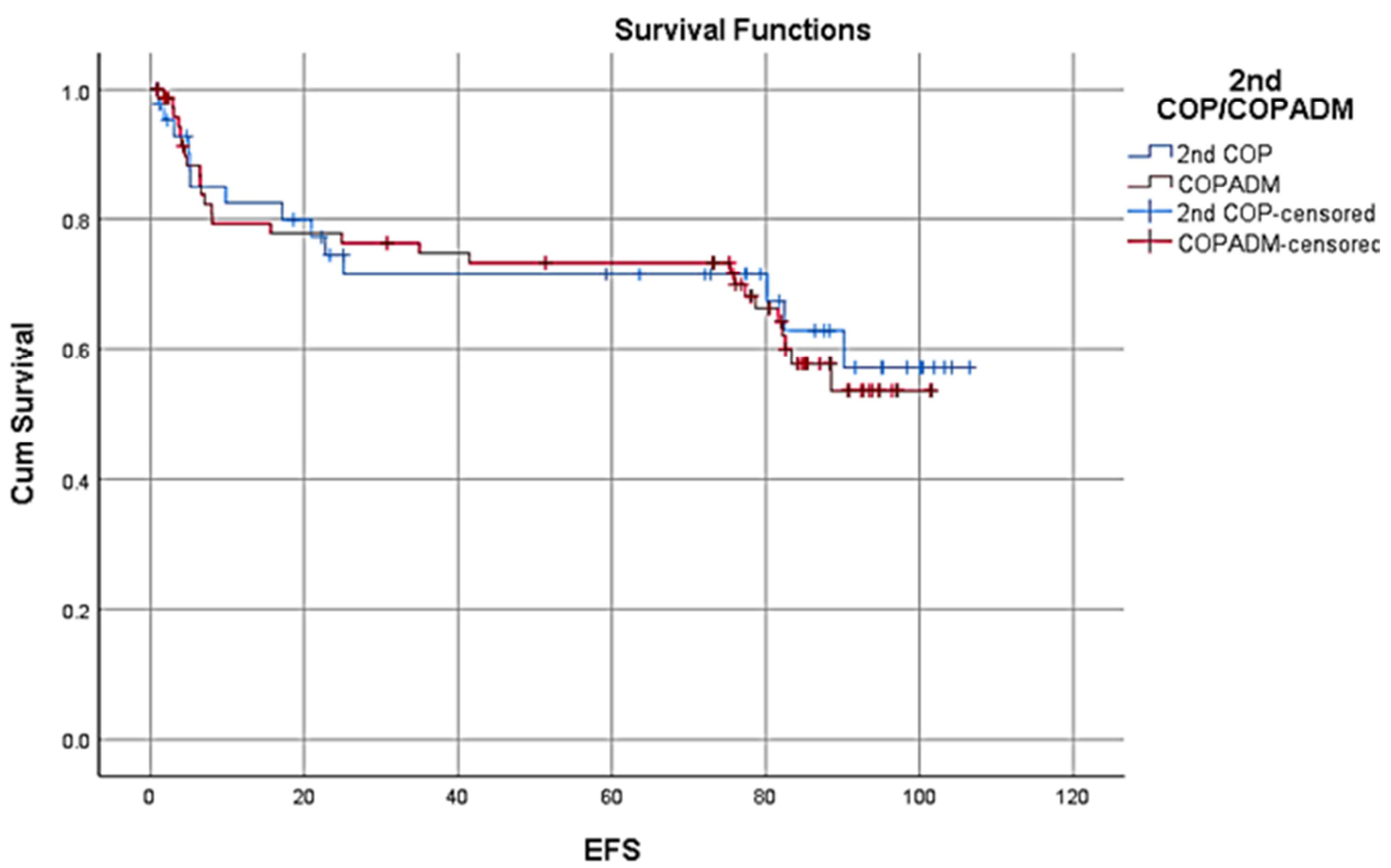

Figure 2. 5 years Event Free Survival among delayed patients who received $2^{\text {nd }}$ CVP 71.5\% (57.2- 85.8). Versus delayed patients who received COPADM was 73.3\% (62.5-84.1), (P value 0.81)

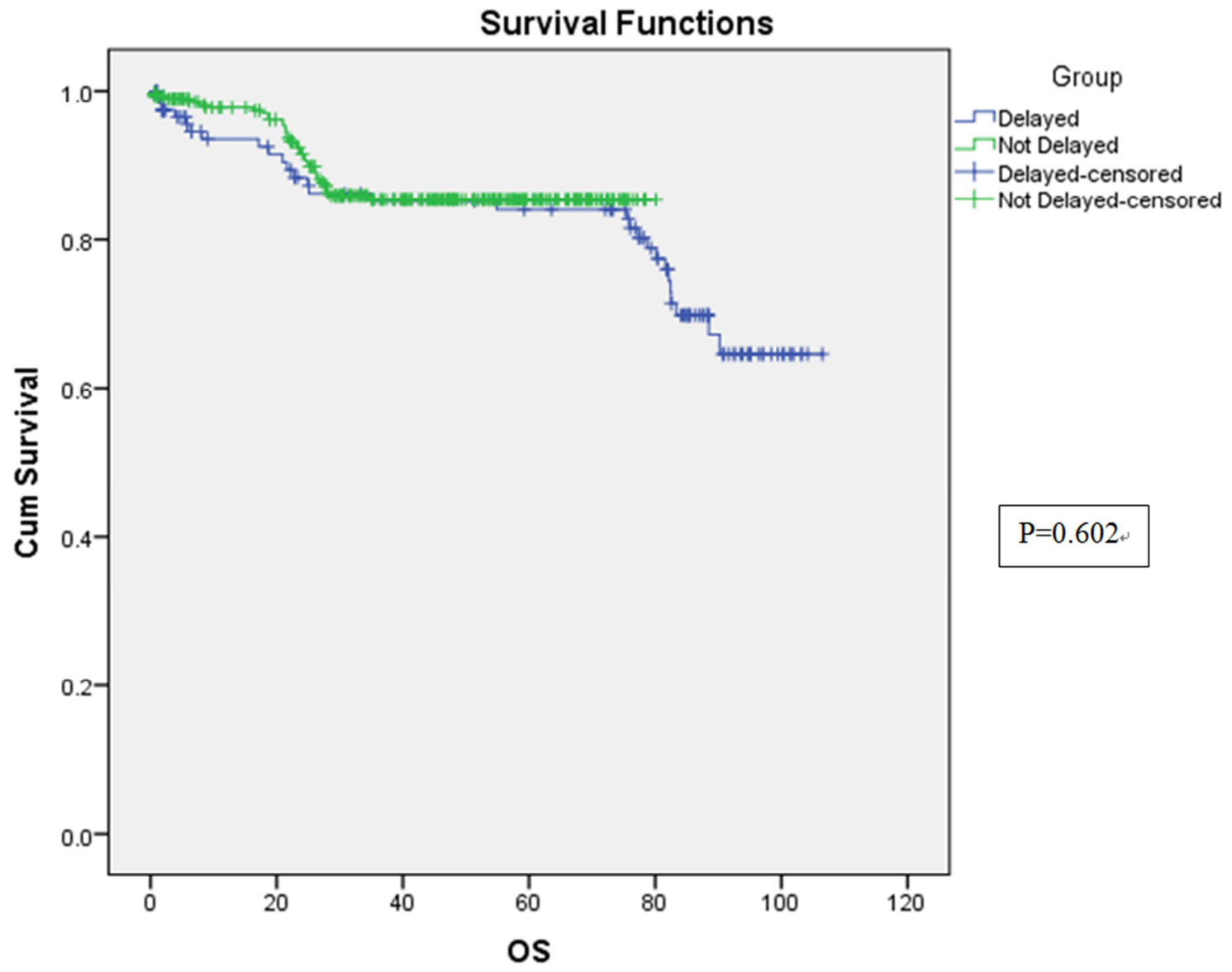

Figure 3. 5 years overall survival among delayed patients was $84 \%$ (st.error 3.7\%), and among non-delayed patients was $85.9 \%$ (st. error $2.2 \%)$. 


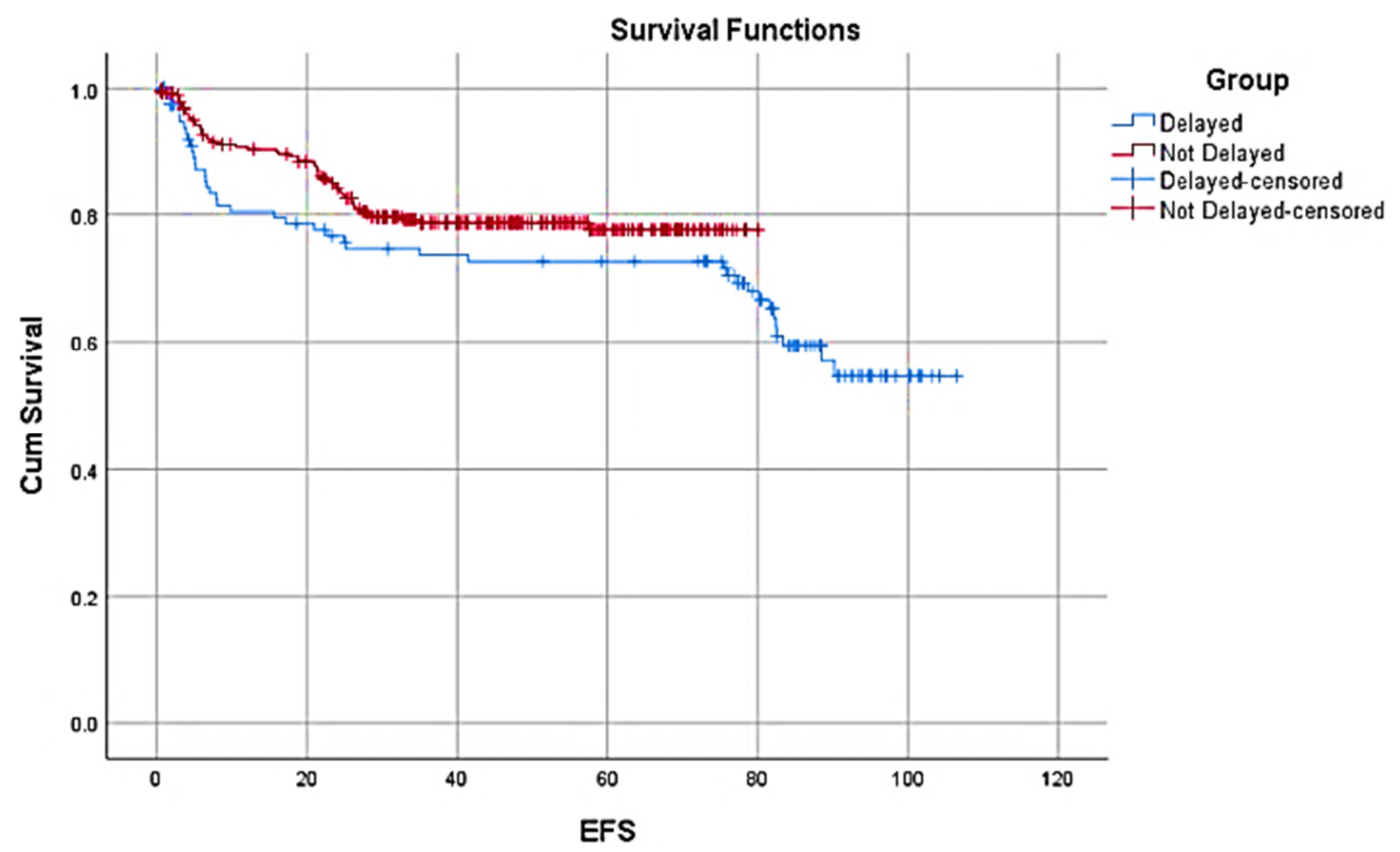

Figure 4. 5 years overall survival among delayed patients was 72.7\% (64.3-81.1), and 77.6\% (72.3-82.9) among non-delayed patients, (P value 0.169).

\section{Discussion}

Lymphomas represent more than $8-10 \% \%$ of malignancies in children and adolescents [6]. The most prognostic factors for NHL patients are the stage of disease, response to treatment and supportive care to treatment toxicity [7]. Delayed diagnosis, aggressive stage at presentation, malnutrion at presentation all affecting response to treatment and increase incidence of organ toxicity in response to chemotherapy [8- 10]. Tumor lysis syndrome of rapidly growing tumors, as Burkitt lymphoma, is characterized by electrolytes and renal disturbance. TLS is potentially fatal [11]. Also High-dose MTX is a major cause of toxicities as gastroenteritis, MTX encephalopathy $[12,13]$.

In Pakistan, (like Egypt) children with Burkitt's NHL presented with stage 3 disease in $91 \%$ of cases and

stage 4 disease in the remainder, stages that are associated with much higher morbidity, mortality, and costs of care [14].

Intensive chemotherapy is needed to achieve a maximum anti-lymphoma effect for high survival rates. Therefore, supportive care during the first few weeks of diagnosis is one of the biggest challenges in LMIC. Use of a low-intensity pre-phase, intensive nutritional support, management of infections

and aggressive hydration to prevent TLS effectively reduces early toxic death [15].

Toxic death in the first month of therapy can be as high as $10 \%$ [16], but it may be up to $30 \%$ in higher-risk patients in LMIC (low middle income countries) [17]. Patients whose diagnosis is delayed present with more advanced disease and a higher risk of malnutrition, TLS, comorbid infections and great risk for early toxic death.

$2-5 \%$ of patients died within a few hours of arrival to the hospital before even completing staging evaluation [15]. Nutritional deficiencies in some settings may also increase the risk of early toxicity, and chemotherapy dose modifications may be necessary in these cases [17].

LMB 96 protocol [1] has stated clearly that patients who are severely ill or having organ toxicity can have a second pre-phase therapy before they start Induction. Our study aim was to analyze those patients and see if delaying their induction in a highly proliferating malignancy as Burkitt's lymphoma had any impact on the outcome of their disease. We had 24 patients who died at induction phase $12.5 \%$ of them were delayed and had 2nd CVP while $25 \%$ of them were delayed and had full induction therapy and $62.5 \%$ were not delayed and although received induction on time, they died during induction either out of toxicity and organ failure or out of sepsis. Although those are small numbers and statistical analysis was not feasible, it was concluded that Delay is essential for critically ill patients in induction for saving their lives and that a second pre-phase (CVP) is of more benefit to those patients.

In a Moroccan study of burkitt's lymphoma with a mean delay to diagnosis of 41 days (range 10 days-2 months). Complete remission was seen in $59 \%$ of cases. At a median follow up of 45 months disease free survival was 54\% [18].

In a Mexican study 121 patients were submitted to a treatment regimen (protocol 8001) and compared with 26 historical controls treated only with the COP regimen, consisting of cyclophosphamide, vincristine, and prednisone. 
With a median of 39 months, the actuarial rate of disease-free survival was $69 \%$ at 2 years and $63 \%$ at 6 years, compared with $36 \%$ at 6 years of the control group (COP)

$$
(\mathrm{p}<0.01) \text { [19]. }
$$

There are limited evidence-based practice guidelines and literature available that provide guidance for chemotherapy changes in pediatric patients with Burkitt's lymphoma who are in a poor general condition, or suffering organ dysfunction.

Trials to decrease the doses of systemic methotrexate and IT cytarabine along with altering the fractionated schedule for cyclophosphamide were designed to reduce the substantial treatment-related toxicity, primarily mucositis, CNS toxicity, and prolonged myelosuppression [20].

Publications about delaying therapy in children with Burkitt's lymphoma according to patients' condition at diagnosis are scarce.

Out of the 122 patients who were delayed only 16 (13\%), had relapse, or disease progression while $(15.9 \%)$ patients had relapse from the non-delayed group, which denotes that giving less intensive chemotherapy during induction period is not affecting the outcome of critically ill Burkitt's lymphoma/leukemia patients.

The overall survival among the group who were delayed then received 2nd pre- induction phase chemotherapy (CVP), versus those who were delayed then received induction phase chemotherapy was $(76.1 \%)$ (st.error 7\%), ( 88.7\%) (st.error $4 \%)$ respectively $(\mathrm{p}=0.369)$. The overall survival between both groups were statistically insignificant, hence a second prophase is not superior to induction therapy for delayed patients.

The overall survival in patients, who were delayed versus who were not delayed was (84\%) (st.error 3.7\%), (85.9\%) (st.error $2.2 \%)$ respectively $(\mathrm{P}=0.602)$. This insignificant relation, denotes that delaying chemotherapy in ill patients will not affect the survival.

More extended randomized studies are needed discussing very sick patients presenting with high tumor burden burkitt's lymphoma and best approach to treat them with minimizing toxicity from therapy.

\section{Conclusion}

In critically ill patients delay of chemotherapy in induction phase is important to reduce morbidity and mortality. The Delay of chemotherapy has no impact on OS in Burkitt's lymphoma/leukemia patients. A second pre-phase therapy in our opinion should not be adopted for all sick patients with organ toxicity who will not tolerate intensive therapy during early phases of treatment, but instead we recommend a recovery from organ toxicity and starting intensive therapy (COPADM) rather than giving a $2^{\text {nd }}$ CVP of course with careful surveillance of disease progression.

\section{Acknowledgements}

I gratefully acknowledge my colleagues in NHL study team member in Children Cancer Hospital Egypt, and my patients.

\section{References}

[1] Cairo MS, Raetz E, Lim MS, Davenport V, Perkins SL. Childhood and adolescent non-Hodgkin lymphoma: new insights in biology and critical challenges for the future Pediatr Blood Cancer 200545 (6) 753-769.769.

[2] Swerdlow SH, Campo E, Harris NL, Jaffe ES, Pieleri SA, Stein $\mathrm{H}$, et al. WHO classification of tumors of haematopoietic and lymphoid tissues. 4th ed. Lyon: IARC; 2008. ((IARC WHO Classification of tumours, n.2).

[3] Ferry JA. Burkitt's lymphoma: clinicopathologic features and differential diagnosis Oncologist 200611 (4) 375-383.383.

[4] Buckle, G, Maranda, L, Skiles, J, et al. Factors influencing survival among Kenyan children diagnosed with endemic Burkitt lymphoma between 2003 and 2011: a historical cohort study. Int J Cancer. 2016; 139: 1231- 1240.

[5] Magrath, IT. Treatment of Burkitt lymphoma in children and adults: lessons from Africa. Curr Hematol Malig Rep. 2006; 1: $230-240$.

[6] LAILA M. SHERIEF, 1, 2 USAMA R. ELSAFY, 1 ELHAMY R. ABDELKHALEK, 1, 2, et al, Disease patterns of pediatric non-Hodgkin lymphoma: A study from a developing area in Egypt. Mol Clin Oncol. 2015 Jan; 3(1): 139-144.

[7] Catherine Patte, Anne Auperin, Jean Michon, et al, The Société Française d'Oncologie Pédiatrique LMB89 protocol: highly effective multiagent chemotherapy tailored to the tumor burden and initial response in 561 unselected children with B-cell lymphomas and L3 leukemia , Blood 2001 97:3370-3379;

https://doi.org/10.1182/blood.V97.11.3370

[8] Hesseling, P, Israels, T, Harif, M, Chantada, G, Molyneux, E. Practical recommendations for the management of children with endemic Burkitt lymphoma (BL) in a resource limited setting. Pediatr Blood Cancer. 2013; 60: 357- 362.

[9] Cervio, C, Barsotti, D, Ibanez, J, Paganini, H, Sara Felice, M, Chantada, GL. Early mortality in children with advanced mature B - cell malignancies in a middle - income country. J Pediatr Hematol Oncol. 2012; 34: e266- 270.

[10] Armando Peña - Hernandez, Roberta Ortiz, Claudia Garrido , et al, Outcome of pediatric non - Hodgkin lymphoma in Central America: A report of the Association of Pediatric Hematology Oncology of Central America (AHOPCA), First published: 24 January 2019, https://doi.org/10.1002/pbc.27621.

[11] Yohannes Belay, Ketsela Yirdaw and Bamlaku Enawgaw 2 Tumor Lysis Syndrome in Patients with Hematological Malignancies, J Oncol. 2017; 2017: 9684909.

[12] Tsurusawa M1, Gosho M1, Mori T2, et al, Statistical analysis of relation between plasma methotrexate concentration and toxicity in high-dose methotrexate therapy of childhood nonHodgkin lymphoma, Pediatr Blood Cancer. 2015 Feb; 62(2):279-284. doi: 10.1002/pbc.25305. Epub 2014 Oct 30 . 
[13] Woessmann W, Seidemann K, Mann G, Zimmermann M, Burkhardt B, Oschlies I, Ludwig WD, Klingebiel T, Graf N, Gruhn B, Juergens H, Niggli F, Parwaresch R, Gadner H, Riehm H, Schrappe M, Reiter A, BFM Group The impact of the methotrexate administration schedule and dose in the treatment of children and adolescents with B-cell neoplasms: a report of the BFM Group Study NHL-BFM95 Blood 2005105 (3) 948-958.958.

[14] Faizan, M., Anwar, S. \& Khan, S. (2018) Demographics and outome in paediatric non-Hodgkin lymphoma: single centre experience at The Children Hospital Lahore, Pakistan. Journal of the College of Physicians and Surgeons Pakistan, 28, 48-51.

[15] Cairo, M. S., Coiffier, B., Reiter, A. \& Younes, A.; TLS Expert Panel. (2010) Recommendations for the evaluation of risk and prophylaxis of tumor lysis syndrome (TLS) in adults and children with malignant diseases: an expert TLS panel consensus. British Journal of Haematology, 149, 578-586.

[16] Gaytan-Morales F, Alejo-Gonzalez F, Reyes-Lopez A, et al: Pediatric mature B-cell NHL, early referral and supportive care problems in a developing country. Hematology. 2019 Dec; 24(1):79-83 doi: 10.1080/10245332.2018.1510087. Epub 2018 Aug 27.
[17] Guillermo Chantada1 Catherine G. Lam, 2 and Scott C. Howard. Optimizing outcomes for children with non-Hodgkin lymphoma in low- and middle-income countries by early correct diagnosis, reducing toxic death and preventing abandonment British Journal of Haematology, 2019, doi: 10.1111/bjh. 15785

[18] N. Otmani, M. Khattab: Oral Burkitt's lymphoma in children: the Moroccan experience. Int. J. Oral Maxillofac. Surg. 2008; 37: $36-40$.

[19] Rivera-Luna, Roberto M.D.; Martinez-Guerra, Guillermo M.D.; Martinez-Avalos, Armando M.D.; Altamirano-Alvarez, Eduardo M.D.; Ayon-Cardenas, Ana M.D.; Cardenas-Cardoz, Rocio M.D.; Borrego-Roman, Rigoberto M.D.; LancheGuevara, Teresa M.D.; Lopez-Corella, Eduardo M.D. Treatment of Non-Hodgkin's Lymphoma in Mexican Children: The Effectiveness of Chemotherapy During 13 Malnutrition. [Miscellaneous] American Journal of Pediatric Hematology/Oncology. 9(4):356-366, Winter 1987.

[20] Lacasce A, Howard O, Lib S, et al. Modified magrath regimens for adults with Burkitt and Burkitt-like lymphomas: preserved efficacy with decreased toxicity. Leuk Lymphoma 2004; 45:761-7. 